\title{
Facilitating the Acquisition of Critical Writing Skills? An Exploration of Pedagogical Practices Within a Business School at a New University in the UK
}

\author{
Martin Percy \\ University of Westminster \\ M.Percy@westminster.ac.uk
}

\begin{abstract}
This case study of writing practices at a Business School at a "new university" attempts to ascertain whether a constructivist and dialogic pedagogical approach is utilised in order to facilitate the acquisition of critical writing practices among predominantly undergraduate non-traditional students. Constructivist learning theory assumes that knowledge is constructed by individuals through a phenomenological subjective interpretation of experience. Hence learning is a dialectic process resulting from a synthesis between preconceived ideas and reflections on experience. It is assumed that a student-centred dialogic approach to teaching is likely to facilitate learning and the acquisition of the higher critical skills within the disciplinary context. Therefore, dialogic feedback plays a crucial role in the learning process and guidance on the pre-writing tasks of selecting and evaluating source material, planning, feedback and disciplinary interpretations of criticality are likely to have an impact on the production of academic texts. The research triangulated semistructured interviews with academics and students and incorporated an examination of educational artifacts. The paper concludes that assumptions of the unidirectionality of student-teacher relationships and a perception that the acquisition of critical skills is external to disciplinary practice may have mitigated against a truly dialogic approach to facilitate critical writing. In addition, the increasing marketisation of higher education and promotion of generic attributes to produce employable graduates has seemingly led to an emphasis of reproducing institutional normative perspectives and writing practices, thus blurring the distinction between education and training.
\end{abstract}

\section{Introduction}

This paper aims to explore and identify the social and context dependent discourse practices in a Business School at a "new university" (a former Polytechnic prior to 1992) in the United Kingdom in order to ascertain whether an effective pedagogical approach is used to facilitate the acquisition of critical writing skills on a first year undergraduate core module. The Dearing Report (1997) emphasised the importance of incorporating generic student attributes and skills within academic disciplines in Higher Education (HE) in the UK, which were directly and easily transferable to other contexts, such as the workplace, as universities increasingly came under market pressure to produce "employable" graduates through the development of applicable skills and experience (Moreau \& Leathwood, 2006). The Quality Assurance Agency (QAA) for Higher Education in the UK is an independent body which is responsible for monitoring and advising on the standards and quality of higher education in the country. It emphasises that the higher critical thinking skills of analysis, synthesis and evaluation are desirable transferable student attributes, which should feature as essential 
criteria for grading written assessments in Higher Education (QAA, 2015). Although skills may be directly imparted through instruction, constructivist learning theory assumes the acquisition of abilities to be facilitated through creative social interaction and the distinction between training (imposing conformity to established patterns of behaviour) and education (facilitating creativity) may be considered to be one of the fundamental differences between further and higher education (Widdowson, 1983). Willingham (2007) maintains " that critical thinking is not a set of skills" (p. 10) that can simply be acquired but requires domain knowledge and social practice within the contextual domain. Independent thinking entails critically evaluating different theories and perspectives and coming to a reasoned judgement about which best fits a particular purpose in a particular situation without deferring to prevalent ideologies disseminating socially prescribed knowledge but instead, challenging dominant perspectives. It is therefore reasonable to assume that a critical and dialogic constructivist pedagogical approach is likely to facilitate independent thinking and the interrelated skill of critical thinking. This exploratory study will attempt to assess whether practitioners in the Business School at a new university engage with constructivist pedagogical approaches to facilitate the acquisition of critical writing skills. The Business School was chosen for research purposes as a number of modules are likely to prioritise the reproduction of institutional corporate normative behaviour and writing practices, necessitating an accommodationist approach to writing. It is therefore feasible that the increasing level of marketisation of higher education, with its skills driven focus on "employability," mitigates against a dialogic critical approach to writing and that an emphasis on a particular perspective of discourse may blur the distinction between training and education. This study will present an overview of the literature regarding the implications of interactionist theory and disciplinary context for writing practice before moving on to an exploration of the pedagogical approaches practiced in the Business School. It will then consider the implications this may have for the successful acquisition of the higher critical skills within the disciplinary context.

\section{Literature Review}

\section{The implications of interactionist theory for writing practices}

Symbolic interactionism assumes that meaning is created through interpretation, leading to the construction of a shared reality which in turn shapes behaviour. Within this context, it is necessary to consider how language is used and functions within disciplinary discourse and how social interaction informs practice. Wenger (2002, as cited in Jacobs, 2005) therefore regarded disciplinary discourses to be acquired through participation and socialisation within "communities of practice," which facilitate the acquisition of critical writing practices within a disciplinary context. A community of practice $(\mathrm{CoP})$ is likely to construct and describe an ontological position in which a particular social practice is embedded (Jones, 2009), which has significant implications for disciplinary writing practices. It is worth noting that the emphasis on individualism inherent within western culture may obfuscate the value and significance of socialisation (Gee, 2008). Lea (2004) recognised that the concept of communities of practice does not emphasise that multiple such communities may be found within a university and that a student may well be a "peripheral participant" in more than one; particularly in the higher education environment within the UK, where students are encouraged to take elective modules (external to the students' main discipline) as part of their degree programme. Correspondingly, a multiplicity of "academic discourse communities" 
can be identified at universities, which have their own socially constructed conventions in terms of discourse (Swales, 1990).

\section{Social practices and the interrelationship between discourse, text and criticality}

Social practice is viewed as the construction of discourse which emerges from the interrelationships between practices, participants and the mode of communication. Social practice facilitates the acquisition of secondary discourses, which are acquired in the public sphere (Gee, 2008). Writing practices emphasise not simply what people "do" but incorporate how the practices construct individuals as social subjects (Clark \& Ivanic, 1997). Hence, discourse is the sociocultural context and social practice which systematically forms texts. The exploration of discourse is likely to facilitate criticality. In order to initiate disciplinary socialisation, it is therefore important to explore how discoursal features such as social identities, epistemology, power relations, ideologies, concepts, values and beliefs are likely to determine the construction of texts (Wingate \& Tribble, 2012). Text (written, spoken, visual or multimodal) refers to a means of communication which can be "read" and interpreted by "a reader." A text only comes into being when it comes into contact with "readers" and does not refer to the format or context so much as the ideas expressed. Different readers are likely to view a text through a multiplicity of different interpretations. Discourses are assumed to be acquired largely through a process of acculturisation among novice academic writers attempting to gain legitimate peripheral participation rather than through overt instruction.

Atkinson (1997) has suggested that critical thinking could be regarded as a social practice rather than an educational concept. A lack of critical writing skills are often viewed as a deficit and is likely to be interconnected to previous learning experiences. It is suggested that students from collectivist contexts, such as those from Confucian heritage cultures (CHCs) are less likely to regard critical thinking as a powerful tool distinctive or even a desirable activity, although it is a concept which is highly valued in western cultures which embrace individualism. Students from CHCs are therefore likely to struggle with western educational expectations of the application of the higher critical skills. (Hamberley-Fletcher \& Hanley, 2016). Social background is also likely to influence critical writing practices. Primary discourses (acquired in the home environment) are likely to be influenced by parental secondary discourses (acquired through socialisation within institutional, social or organisational settings) in middle class homes. Such early socialisation in turn is likely to facilitate middle class children's transition to secondary discourses (Gee, 2008). This is less likely to be the case for non-traditional students.

\section{The impact of the disciplinary context on writing practice}

The SEEC (formally the South East England Consortium for Credit Accumulation and Transfer) provides Credit Level Descriptors which are used for assessment purposes throughout universities in the UK. SEEC (2016) defines "problem solving" at level 4 (first year undergraduate modules) in higher education as "identifying a well-defined focus for enquiry....using a limited and defined range of methods, collecting data from a variety of sources and communicating results effectively in an appropriate format (p. 9)." However, the range of methods, which sources are appropriate and the format through which communication occurs are likely to be contentious. The SEEC (2016) goes on to define "analysis and evaluation" at level 4 in higher education to be "judging the reliability of data and information using pre-defined techniques and/or criteria" (p. 9). Which techniques (e.g. analysis may be physical in chemistry but cognitive in psychology) and which criteria are 
used for evaluation (e.g. examining evidence and context, discussing complexities and ambiguities or examining rigour, uncertainty or accuracy) are also likely to be contentious. "Analysis" may be interpreted as the deconstruction of data to facilitate understanding and "critical analysis" as the subjective expression of voice to indicate the stance of the writer, yet how this is achieved is itself subjective to epistemological and disciplinary interpretations. The acquisition of higher critical skills is likely to require a transformative deep approach to learning. However, the dominant outcomes-based approach (output, input, process) to syllabus design; measuring competencies for assessment guidelines, arguably only facilitate a surface approach to learning through the transmission of socially prescribed knowledge to achieve the requisite benchmarks.

Whether generic attributes are universal and are external to the disciplinary context is contentious, as such attributes may be perceived to be implicitly determined by the disciplinary context and subject to multiple interpretations. Jones (2009) focused on perceptions of generic skills and attributes in five academic disciplines: physics, history, economics, medicine and law. The generic attributes examined were critical thinking, problem solving and communication. Conceptualisations of "problem solving" were found to vary according to the subject area, the epistemological assumptions within the discipline, the methodology used and conventions regarding verification of data within the discipline. History, for example focused on causality, whereas physics is more reliant on mathematics for analysis. In history, "communication" was understood as essays, class discussions and presentations. In contrast, physics conceptualises communication in terms of laboratory reports. In short, social sciences study actions which have reasons, good and bad, which are not based on laws, but decisions made by individuals. Natural sciences study events which have causes subject to laws.

Academic disciplines differ in terms of the underlying paradigmatic assumptions and this has implications for criticality in writing practice. The theoretical and conceptual assumptions which constitute the foundations of a paradigm are likely to determine the limitations and form of disciplinary criticality. Different discourses arise from different conceptualisations of prescribed knowledge and this leads to variations in "patterns of language" (Bangeni \& Kapp, 2006, p. 68). Within a constructivist epistemological paradigm, reality is "socially constructed, contingent and local" (Ivanic, 1998, p. 309) and conceptualised in terms of the social context and the perspective of the individual. Therefore, empirical evidence ad the perspectives of participants are paramount to establish plausible inductive argumentation. In contrast, a positivist paradigm emphasises an objective reality, independent of individuals' perceptions and the social context through which "objective universal truths" (Ivanic, 1998, p. 309) can be determined through scientific analysis. Vocational degrees (such as Finance and Accounting degrees within a Business School) often tend to take a more eclectic position with different modules within a degree course assuming different epistemological positions.

Lea and Street (1998) conducted in-depth interviews with students and academic staff in order to ascertain perspectives on literacy practices and requirements within their specific disciplines across the humanities, social sciences and natural sciences. They also engaged in ethnographic participant observation of group sessions and analysed samples of the students' writing along with handouts on essay writing and feedback. Although there was a broad consensus amongst academic staff that structure and argumentation were crucial aspects of academic essay writing, there was a lack of consensus as to how they were realised in 
practice. Lea and Street (1998) suggest that an implicit understanding of what such terms refer to is based more on underlying disciplinary epistemological structures and comment on the tendency of lecturers to focus on surface features such as grammar, punctuation and spelling in written feedback. Wingate (2015) argues that feedback on surface errors is not formative as it does not recognise the real learning requirements of student and cannot lead to transformative practices. Thus, a "good" academic essay is likely to be one that constructs the world in a manner that reflects an individual or socio-cultural disciplinary perspective. The students themselves appeared to be aware that a diverse range of writing practices were required. "Switching" between writing practices could cause confusion and guidelines were not regarded as particularly helpful. In a later study, Lea (2004) emphasises that students increasingly encounter interdisciplinary and multidisciplinary contexts reflecting a variety of disciplinary conventions and epistemologies, especially on vocational degrees. Thus, observation of the socio-cultural practices surrounding the construction of discourse (rather than simply focusing on the texts themselves) are crucial to understanding what might be considered to be "good" or "appropriate" disciplinary writing practice.

\section{Method}

This study assumes writing practices are facilitated by disciplinary socialisation and that guidance on the pre-writing tasks of selecting and evaluating source material, planning, academic writing and feedback are likely to have an impact on production. These processes are therefore explored in the analysis. Questionnaires, incorporating both open and closed questions, were initially completed by the four academics participating in the study in order to establish their expectations of undergraduate students in relation to the construction and interpretation of academic texts and to contextualise perceptions of their students' abilities to meet the requisite demands and the challenges they consider students face in text construction. Following the completion of the questionnaires, semi-structured interviews with the participating academics and four first year Business students were conducted in order to explore a framework of themes relating to disciplinary writing practices on a first year undergraduate core module (Table 1). The interviews with both students and lecturers were all between 45 minutes and one hour long. The participating lecturers all taught on the same core module, which is compulsory for all first year undergraduates on all degrees run by the Business School. "Claire", "Jenny", "Sandy" and "Rachel" (assumed names are used for all participants involved in this paper) were respectively lecturers in Human Resources, Economics, Accountancy \& Organizations and Economics \& Society so the content of the core module in question was not necessarily within their areas of specialisation. The participating lecturers had between three and thirty years of experience and ranging in terms of seniority from lecturers to a Director of Studies. Two of the lecturers were from Asia ("Jenny" and "Rachel"), one was from a European country ("Claire") and the other was British ("Sandy"). Their diverse backgrounds were considered potentially relevant, as areas of specialisation, age, nationality, experience and position may influence the perceptions of appropriate writing practices. The four participating students were Japanese ("Peter"), Italian ("Jade") and the other two were "non-traditional" home students ("Mary" and "Toby"). The interviews were conducted in the second semester so the students had had time to reflect on and respond to the feedback they had received on their assessments in the first semester and therefore had insights of the lecturers' perceptions of their writing practices. All the participating students were also studying on inter-disciplinary English for Academic Purposes (EAP) modules in the second semester and were therefore able to reflect on a range of 
disciplinary academic discourses and written genres explored on the EAP module through discourse analysis.

The participating "non-traditional" home students had progressed from the Business and Technology Education Council (BTEC) National Certificate or Diploma courses and through a Level 3 Foundation course (with a minimum entry requirement of a pass). The two foreign students were required to have a minimum overall IELTS score of 6.0 overall with a minimum of 5.5 in each component of the examination. They were therefore regarded as having the requisite generic language skills to successfully engage in the writing practices of the discipline in terms of the requisite SELT (Standard English Language Test) grades. Ethical clearance was received from the university and all participants, having been informed of the aims of the research and assured that their anonymity would be respected, consented to participation.

The study was triangulated with an examination of assessment marking criteria and samples of students' written assessments. The assessments were essays, which incorporated student reflections on the initial formative feedback provided by lecturers on their first drafts and how this could influence the redrafting of the assessment, the lecturers' comments on the student reflections, the plan for the final essay, the final draft of the essay and the lecturer' subsequent summative feedback. Data for subsequent analysis were therefore obtained from the questionnaires, transcribed interviews with students and academics, grading criteria and the student assessments provided. The assessments included formative feedback, student reflections on the feedback and the final summative feedback on student responses to the feedback; writing style; referencing; the development of argumentation; use of reading and research and application of the concepts explored. The data were colour coded and categorised on Nvivo 11 to signify the themes of perceptions of undergraduates' writing practices, assessing students' writing, perceptions of generic attributes explicitly referred to in the grading criteria, critical reading, aiding students with assessments through formative feedback and perceptions of critical writing practices with the aim of facilitating an emergent analysis. The interviews themselves explored the themes outlined below (Table 1) to take account of staged guidance on the pre-reading tasks of understanding the assessment criteria and selecting, evaluating and critically engaging with source material and responses to and perceptions of feedback. The students reflections on the experience of teacher-student interactions and whether this facilitated the development of writing skills were taken into account and coded.

Table 1: Themes discussed in the interviews with academics and students

\begin{tabular}{|l|l|l|}
\hline Global theme & Main themes & Sub-themes \\
\hline $\begin{array}{l}\text { Pedagogical approaches to } \\
\text { facilitating the acquisition of } \\
\text { critical thinking skills within } \\
\text { the disciplinary context }\end{array}$ & $\begin{array}{l}\text { Assessments and marking } \\
\text { criteria on the core module }\end{array}$ & $\begin{array}{l}\text { Perceptions of students' } \\
\text { ability to meet the criteria } \\
\text { Perceptions of the } \\
\text { appropriacy of the criteria } \\
\text { for grading }\end{array}$ \\
\hline
\end{tabular}




\begin{tabular}{|l|l|l|}
\hline $\begin{array}{l}\text { Interpretations of generic } \\
\text { attributes within the } \\
\text { assessments }\end{array}$ & $\begin{array}{l}\text { Interpretations of generic } \\
\text { attributes } \\
\text { Facilitating student } \\
\text { acquisition of generic } \\
\text { attributes within the } \\
\text { disciplinary context }\end{array}$ \\
\hline $\begin{array}{l}\text { Critical reading (to inform } \\
\text { writing) }\end{array}$ & $\begin{array}{l}\text { Students' ability to evaluate } \\
\text { texts } \\
\text { Identifying conflicting } \\
\text { viewpoints within the } \\
\text { literature } \\
\text { Assisting students to acquire } \\
\text { critical reading skills }\end{array}$ \\
\hline & $\begin{array}{l}\text { Monologic or dialogic } \\
\text { feedback? } \\
\text { Evaluating the effectiveness } \\
\text { of feedback }\end{array}$ \\
\hline students & $\begin{array}{l}\text { Critical or } \\
\text { accommodationist } \\
\text { approaches to writing? }\end{array}$ \\
\hline
\end{tabular}

\section{Findings}

\section{Written assessments and perceptions of first year undergraduates' writing practices}

The predominant written genres for students studying within the core modules were essays and reports of between 1500 and 3000 words. The essay on the core module, compulsory to all undergraduate students on all degree courses within the Business School, followed a collaborative group presentation to facilitate the development of organisational and spoken communication skills. In the interviews, "Rachel" suggested that using headings, tables and charts enables students to structure reports more easily than mastering the cohesive paragraph transitions within essays but it was recognised by "Jenny" that students generally seemed more familiar with essays and were often confused by the suggested layouts of reports.

The participating academics had previously acknowledged in the questionnaires that "nontraditional" home students appeared not to have previously been "taught" academic writing and experienced problems in terms of cohesion and coherence ("writing in a clear way" and "getting the focus right"). In the interview, "Rachel" asserted that the overseas students (predominantly CHC students) experienced difficulty "getting to the point" and "illustrating the point with examples." She suggested this was due to the requisite schemata not featuring in Asian writing. Both participating students and academics referred predominantly to surface features, such as grammar, spelling and punctuation, as being particularly problematic aspects of writing. Rachel asserted (in the questionnaire) that "using contractions, appropriate style and a tendency to write in the second person." One student ("Peter") considered "grammar to be a very big problem" ("I forget to put 'the' or 'a' in"). The module marking criteria itself stipulates that "a well-written answer in clear English" and "mastery of academic style" are necessary to achieve a high grade. 
In the interviews, it emerged that pre-marking meetings to standardise marking procedures for all assessments enabled precedents of interpretations of marking criteria to be established by the module leader. "Jenny" observed that as a result of this process, some lecturers (including herself) subsequently gave higher grades than they would have deemed appropriate if left to interpret the evaluation criteria for the assessments by themselves and that lecturers had become more lenient in terms of grading.

\section{Interpretations of generic attributes explicitly referred to in the grading criteria}

The participating academics acknowledged in the questionnaire that students were expected to "write critically." There were also explicit references in the generic marking criteria to "the ability to offer a competent analysis of primary data, to evaluate and criticise source material and to show a full awareness of problems and potential solutions" as being essential to achieving a high grade in assessments on core modules. However, there appeared to be considerable ambiguity in how the attributes of problem solving, analysis and criticality were to be interpreted by both students and academics. Although an inability to write critically was recognised as a common problem, "Jenny" ventured that there was insufficient time to "teach such skills" in addition to the course content within the limited time constraints of the modules and that students would simply "have to keep doing it until they get it right." The participating academics' perceptions of problem solving (explored in the interviews) are summarised in Table 2 below:

Table 2: Conceptualisations of problem solving within the disciplinary context

\begin{tabular}{|l|l|}
\hline Academic participant & Interpretations provided by participants \\
\hline "Rachel" & $\begin{array}{l}\text { Finding a solution to a problem by means of } \\
\text { establishing the relevant tools to do so and } \\
\text { "applying existing theories or concepts onto } \\
\text { the data." Entails finding an efficient } \\
\text { method or theory to solve problems, } \\
\text { necessitating reflection on mistakes made in } \\
\text { the past. }\end{array}$ \\
\hline "Claire" & $\begin{array}{l}\text { Answering the question by trying to find } \\
\text { exactly what the core question being asked } \\
\text { is. }\end{array}$ \\
\hline "Jenny" & $\begin{array}{l}\text { Making sense of phenomena through } \\
\text { analysis with the implication being what } \\
\text { you can do to make things better. }\end{array}$ \\
\hline "Sandy" & $\begin{array}{l}\text { Regarded problem solving as intrinsic and } \\
\text { illustrated (in the class) how students would } \\
\text { be provided with a situation that they could } \\
\text { deconstruct into components. Numerical } \\
\text { solutions formulated for various issues and } \\
\text { then a solution could be reconstructed at the } \\
\text { end. Enables students to experience problem } \\
\text { solving when teaching Excel. It would be } \\
\text { necessary to identify the right tools to } \\
\text { undertake analysis in order to make sense of }\end{array}$ \\
\hline
\end{tabular}


Although the responses indicated an awareness of the necessity of "identifying the right tools" and "finding an efficient method" there was limited evidence (in terms of examination of the feedback or observations made by academics or students in the interviews) that what the relevant tools or methods were considered to be had been successfully communicated to the students. One student ("Mary") understood problem solving as "showing a graph and explaining what it means" or "discussing an issue and providing recommendations or solutions". "Peter" suggested "discussing the issue and giving a solution." "Jenny" understood analysis to be "the ability to use a relevant framework to make sense of and predict phenomena". She considered that she had only recently realised that students did not understand what analysis meant after finishing teaching "theory", (despite having had a number of years of teaching experience) and that it was necessary for students to be aware that this is a tool through which knowledge is communicated (rather than the knowledge itself). "Sandy" suggested analysis was "the first part of problem solving in terms of deconstruction" and "Claire" ventured that the term referred to "not just considering what was positive or negative about a particular theory but also using empirical examples to substantiate points and to venture to establish a position through voice". She was unable to offer a clear distinction between problem solving and critical analysis. One student ("Jade") suggested that analysis entailed applying existing methods, theories or concepts onto data or if an inductive approach is used, identifying theories which may emerge from the data. It was emphasised that it was not simply identifying the positive and negative aspects of a theory but entailed using empirical evidence and theoretical considerations to substantiate a position. Another student ("Mary") opined:

Analysis is like discussing and kind of breaking up something, for example, or pointing out like explaining the different points of something and bringing it together and evaluating why it is what it is; good points or bad points about a particular theory....using maybe practical examples to back it up and maybe give your opinion based on the theory and the practical examples you have used.

"Claire" suggested critical thinking encompassed challenging received wisdom and "exploring the underlying theoretical constructs to identify shortcomings," and "putting forward different perspectives." She asserted that a thorough examination and understanding of the ambiguities and complexities of the issues under investigation was considered unrealistic for first year undergraduate students. "Sandy" suggested that at undergraduate first year level, "putting forward two ideas instead of one" rather than simply describing would be a more realistic and realizable aim or being able "to reach a conclusion on the basis of the evidence presented". Students were expected to describe rather than write critically and she interpreted level 4 criticality as "describing with a bit of thought."

The students participating in the interviews appeared to recognise the concept of critical thinking but were rather confused as to its disciplinary applicability. "Mary" defined criticality as "asking questions to find out why something is and what makes him say that" (sic). "Claire" suggested "how to say something in a different way" or "not taking something Journal of Contemporary Issues in Education, 2020, 15(2), pp. 104-119.

(c) Author(s), Creative Commons Attribution 4.0 (CC BY 4.0) licence http://ejournals.library.ualberta.ca/index.php/JCIE 
at face value" but identifying the underlying issues and "the shortcomings of the theory and whether the theory is completely foolproof and whether the authors were subjective or objective" (sic). Closely related to the concept of critical writing is the use of "voice" to express a stance. "Jenny" acknowledged explicitly informing students that they could voice their opinion in the third sentence of a paragraph after citing sources for the first two sentences. She noticed "only a few of the students got this" and suggested that perhaps "she was not teaching them well enough."

\section{Critical reading}

Writing practices emphasise the social aspects of writing, embedded in a social context. An exploration of writing practices therefore necessitates considering socially and ideologically constructed patterns of behaviour such as organizing work by searching for and evaluating potential source material and planning prior to writing (Clark \& Ivanic, 1997). Approaches to facilitating critical reading are therefore crucial. In the questionnaire, the lecturers acknowledged that they did not consider the students able to read complex academic texts, to engage in critical reading or to critique arguments when reading. "Sandy" suggested that students needed "to learn how to establish the links between references in order to understand the context of what they are reading and differentiate between different types of publications."

In the interviews, the academics acknowledged that many first year students have difficulty identifying, evaluating and selecting source material. A common perception of the academics (which emerged through both the questionnaires and the interviews) was that the students "were not reading widely enough." The stronger students would appear to read core textbooks and a few sources suggested on the reading lists but most first year students had difficulty reading academic texts, understanding the meaning and paraphrasing or distinguishing "relevant" from "irrelevant" content. The academics thought that most students appeared to have had no previous guidance in or experience of evaluating, selecting and integrating relevant material prior to beginning their courses and did not appear to consider the requisite "study skills" required to read critically to be intrinsic to the discipline or feasible considering the time constraints. However, "Jenny" emphasised that she tells students "to be critical because whatever information they receive has been interpreted through the eyes of the author." First year students are discouraged from using newspapers as source material as they are unable to evaluate which might be deemed appropriate (e.g. The Financial Times) and which were not (e.g. The Daily Mail or Metro). On at least one other core module, this had led to a precedent being set to prohibit all newspapers being used as sources. Feedback on reading (provided on one of the essays examined) suggested that the student considers "reading peer reviewed journal articles, credible websites and carefully selected newspaper reports to broaden your research and reading." "Rachel" acknowledged that the acquisition of critical reading skills "was not adequately addressed on modules" within the Business School and that the students themselves "appeared to exhibit a general disengagement with reading." The academics considered the students not to be reading enough in order to grasp the full complexities of the issues addressed in their written assessments. "Sandy" emphasised that the majority of first year students were reliant on Internet sources which they had not evaluated and considered it acceptable to "cut and paste" from unattributed web-based sources. One major challenge identified was a lack of consideration of the context of subject material and differentiating between different genres of publications. An inability to distinguish between conflicting viewpoints within disciplinary Journal of Contemporary Issues in Education, 2020, 15(2), pp. 104-119.

(c) Author(s), Creative Commons Attribution 4.0 (CC BY 4.0) licence http://ejournals.library.ualberta.ca/index.php/JCIE doi 10.20355/jcie29417 
fields was emphasised as a key aspect of critical reading and there was a broad consensus that this was a widespread problem for first year undergraduate students within the Business School. The lecturers considered poor writing practices to stem from a lack of engagement with the literature and insufficient critical skills to evaluate and synthesise source materials, which was widely perceived to be partially due to the student's previous educational experiences seemingly failing to facilitate the acquisition of such skills. The two participating "non-traditional" students ("Mary" and "Toby") commented on there being many words in academic articles which they did not understand and a lack of clarity on how they could be expected to proceed to evaluate a text whilst experiencing difficulty "working out" (i.e. decoding or interpreting) meaning.

\section{Perceptions of feedback and its impact on writing practices. A dialogic approach?}

Bakhtin (1981) considered language to be dialogic and the meaning of words to be determined by dialogue. Words are inextricably connected with the thoughts and perceptions of interlocutors (Vygotsky, 1962) and related to activities that create meaning, described by Wittgenstein (1953) as "language games". A dialogic approach to feedback, which entails interaction between academics and students, is therefore likely to generate a shared understanding (Merry et al, 2013). In the interviews, the informants alluded to the fact that the university runs a personal tutoring scheme, where students received clarification as to how feedback could be used to improve their writing. This suggested there are opportunities for oral dialogue to facilitate a shared understanding leading to transformative writing practices. However, "Rachel" acknowledged that few students appeared to make use of the scheme but was uncertain as to why this was the case. In addition (as mentioned above), students were expected to provide written responses to formative feedback provided (to which academics would respond in the summative feedback) suggesting further opportunities for opening a dialogue. The students acknowledged (in their responses) that they would take the initial feedback (such as "to use more critical analysis" and "proofread work") into account and that they were sometimes "disappointed with the initial grade." The student reflections met with responses from the lecturers indicating that their reflections "were interesting" but that "there were repeated mistakes" and "although the student may be disappointed with the grade, it was necessary to reflect on the feedback to understand the grade." Summative feedback on the writing style and referencing referred to essays being presented as reports, to always proofread work, the writing tending to be disjointed and there being "much room for improvement but this will come with time." Feedback on structure and development of argument on one essay commented on the conclusion being "unsupported and based on the student's opinion, which is not acceptable in academic writing."

In the interviews, "Rachel" observed that only "active" students would take feedback into account but was uncertain as to why other students would not. She acknowledged that a few students would challenge the feedback and that if they could justify their point, she would take account of their arguments. "Jenny" suggested that students had perhaps "run out of time" and although students were likely to be aware that the purpose of the feedback is to aid them in normative writing practices, they had possibly not considered the implications that formative feedback might have on their final grade. "Claire" stressed that students often "did not take the feedback into account." Despite being given "quite clear feedback", the students "tend to make the same mistakes over again." Students were subsequently asked to write a summary on the formative feedback received and what changes they made to improve. "Claire" acknowledged that they would write "I've learnt this...my seminar leader said Journal of Contemporary Issues in Education, 2020, 15(2), pp. 104-119. (c) Author(s), Creative Commons Attribution 4.0 (CC BY 4.0) licence http://ejournals.library.ualberta.ca/index.php/JCIE doi 10.20355/jcie29417 
this...in their reflections but when you look back at the essay it's the same. They are just paying lip service." "Sandy" observed that students were more interested in the mark, which they perceived to be "a badge of their identity" and seemed to take little interest in that the feedback could be used to facilitate the acquisition of more "appropriate" writing practices. Therefore, they were more likely to object to the mark itself rather than the feedback they had received and many students apportioned blame on the course tutors for not enabling them to achieve the grade they aspired to. In the interviews, the students expressed mixed reactions to the feedback. "Mary" considered the feedback to be "pretty clear" and was "quite happy with the feedback." However, she suggested the feedback indicated what needed to be improved rather than how to improve and was informed whether the main idea was "correct or not." "Peter" stated that although he always understood the feedback, "it wasn't helpful as it didn't give me help to improve."

\section{Application of critical skills}

One QAA (2014) descriptor stipulates that level 4 students are expected "to demonstrate the ability to present, evaluate and interpret qualitative and quantitative data in order to develop lines of argument and make sound judgements in accordance with basic theories and concepts of their subject(s) of study" (p. 21). The generic grading criteria for modules at the Business School stipulate that students are expected "to demonstrate a clear ability to evaluate and criticise sources and at least an emerging ability to apply original insight and thought to the issues under discussion" in order to achieve a high grade. In the questionnaires, participating lecturers acknowledged that students were expected to write critical argumentative texts but did not consider their students able to write critically or construct argumentative texts well and that students "find structuring a coherent argument a challenge and tend to reproduce sets of facts." The academics also acknowledged that students were unable to challenge views and ideas by using supporting evidence. In the subsequent interviews, the participating academics were therefore individually asked whether a critical pedagogical approach was used in order to facilitate critical awareness. The participating academics acknowledged that students were at liberty to challenge the dominant ideological stance on core modules and encouraged to take a critical stance towards the texts they engaged with and that the gradual acquisition of critical skills through a process of osmosis was feasible. Nevertheless, "Jenny" recognised that students were expected to "think in a particular way." Some of the lecturers mentioned attempting to raise the students' awareness of the ideological interpretations of news events in newspapers, pointing out (for example) that the Economist took a liberal (right-wing) interpretation of events and the Guardian a centre-left interpretation and indicating how such representations were evident. However, "Sandy" did not believe that such an approach was widely practiced by academics within the Business School nor advocated by module leaders but that it was at the discretion of the individual practitioner. There was a broad consensus that expecting first year students to show an awareness of political and ideological dimensions of discourse was unrealistic and that it would be "unwise to have unrealistic expectations" of first year students' critical thinking skills. "Jenny" emphasised that much of the degree course focused on learning "writing skills" reflecting practices within the workplace but maintained that students are encouraged to express criticality through voice rather than simply summarising and synthesizing the ideas of authorities within the field.

"Rachel" commented on the ambiguity of facilitating education through the development of critical awareness whilst acknowledging the social reality that students are expected to conform to the ideological values and culture of the corporate institutions through which their Journal of Contemporary Issues in Education, 2020, 15(2), pp. 104-119.

(c) Author(s), Creative Commons Attribution 4.0 (CC BY 4.0) licence 
graduates would subsequently be seeking employment. There was a perception that the vocational nature of some of the undergraduate modules meant that the focus was often on "training" rather than "education." "Sandy" emphasised that much of the degree course focused on learning skills reflecting practices within the workplace although acknowledged that the degree should perhaps focus more on education with less emphasis on training by encouraging a critical student voice rather than simply summarising and synthesising the ideas of authorities within the field. She considered the QAA guidelines to be a restraint in that they necessitated the development of generic skills, which would enable students to gain employment through conforming to the organisational culture they would be likely to encounter, crowding out the potential for a more critical approach. "Sandy" also suggested that although many people who teach in academic institutions go into education because they are "mavericks who like the autonomy", they "are expected to produce students who will have to conform." She described many of the students studying within the Business School as being "very conservative" and therefore hostile to challenging dominant ideologies and practices ("you have to be very careful what you say around them"). In contrast however, "Rachel" (an Economics Lecturer) stressed that her students were often rebellious and idealistic and "loved to challenge how wealth was distributed", suggesting a lack of consensus as to whether students would be likely to respond positively to a critical approach to hegemonic discourse.

\section{Discussion}

\section{Generic attributes}

The Business School's grading criteria stipulates that "clear evidence of independent and original thinking in arguments and analysis" as being a crucial attribute to achieve a high grade at level 4 assessments in Higher Education. SEEC (2016) conceptualises "analysis and evaluation" at level 4 as being able "judge the reliability of data and information using predefined techniques and/or criteria" (p. 9). The interviews revealed that the participating academics recognised this but did not consider the facilitation of the acquisition of generic attributes to be their primary responsibility and there appeared to be a limited consideration of pre-defined techniques and criteria for analysis and evaluation. Time restraints were perceived as impeding the potential development of the requisite attributes and priority was accorded to focusing on the communication of disciplinary content. A more critical pedagogical approach exploring the potential range of criteria through which problem solving, analysis and evaluation could be applied within the disciplinary context appeared to be given limited consideration. However, a dialogic pedagogical approach would be likely to entail an examination of political and ideological dimensions, gaps in the literature, conflicting viewpoints, challenging perceived wisdom, values and assumptions inherent within the literature and how power relations influence disciplinary discourse. This would provide ample scope for exploring potential criteria for evaluation, which could be likely to facilitate critical thinking and writing skills.

\section{Critical reading}

The assessment criteria stipulated that "assessments should include references to secondary as well as tertiary sources and should demonstrate an emerging ability to evaluate and criticise sources" and "the quality of argument should show some sophistication and elegance." Critical reading entails an ability to assess whether the writer has sufficiently justified the claims being made; an assessment partially based on what has been 
communicated within the text but also on disciplinary knowledge, experience and inference (Wallace \& Wray, 2006). McGinley (1992) conceptualises successful reading-to-write behaviour as being able to identify essential information to substantiate arguments and recognise inherent inconsistencies and weaknesses. In order to read critically, students would need to be able to challenge the discursive position of the author, ultimately arriving at a "transaction model" recognising how multiple potential interpretations are feasible. This entails progressing from a "transmission model" through which meaning is transmitted directly from the author to the passive reader and the text is viewed as being authoritative (Abbot, 2013, as cited in Wingate, 2015).

Feedback on reading and engagement with appropriate literature provided by the lecturers suggested 'more reading is required to reach your potential' and 'a basic understanding of the concept is shown, but much more could be achieved with a more thoughtful approach'. Such feedback would seem to suggest that a more critical approach is required and may imply that texts are dialogic and multiple interpretations become evident through intertextual exploration to facilitate an awareness of the semiotic history of relevant discourse. This may necessitate the identification of a 'hidden dialogue' existing through engagement with other texts or within the discursive framework of the discipline (Halliday \& Webster, 2000). However, this is unlikely to be evident to the students on the basis of the feedback provided by the academics to the assessments reviewed in this exploratory study and the participating students confirmed that they did not understand how to improve on the basis of the feedback. Further feedback suggested "looking into peer-reviewed journal articles, credible websites and carefully selected newspaper reports to broaden your research and reading" and "not to rely on online case study materials, which lack authority and are limited in scope and depth." The criteria through which discourse is expected to be evaluated as "credible" or how newspapers are to be "carefully selected" is unlikely to be self-evident to the student and a critical approach examining the social context, arguments, evidence and assumptions that shape discourse within the corporate media would be more likely to facilitate critical analysis. This would also establish criteria for critical evaluation.

\section{Feedback}

The students' comments and reflections on feedback would suggest that they view feedback through a dualistic epistemology (Merry et al., 2013), in which the academic's role, as the source of knowledge, is to provide the "correct" template and "answer", which the student is expected to imitate. This misconception is likely to mitigate against facilitating the development of the students' abilities to evaluate or recognise the validity of multiple perspectives and hence develop independent critical thinking skills. The interaction between the student and the lecturer is not necessarily dialogic should the lecturer be "talking at" the student rather than facilitating an exploration of potential interpretations of feedback. Both the students' comments regarding a lack of clarification of how to proceed (e.g. 'to use more critical analysis") and the academics' observations that the requisite transformations had not taken account of the feedback would suggest a lack of exploration regarding interpretations and consideration of the students' epistemological development. In order for the "teacherstudent" interaction to be truly dialogic and transformative, the "unidirectionality of the teacher-student relation" (Lillis \& Scott, 2007, p. 13) needs to be challenged. Kress (2007) recognised the unidirectionality of teacher-student relations to be a common pedagogical assumption and this seemed evident in the observations of both the participating students and academics during the interviews (e.g. "I thought the feedback was pretty clear. They said we 
needed to...") and this in itself may have an impact on learning and perceptions of learning among both students and academics. Students should be able to justify their choices and teachers to question their assumptions in order to facilitate constructive learning. There appeared to be limited recognition from either the participating academics or the students as to what effective dialogue may entail. This was also evident by the low participation rate of students within the personal tutoring scheme, suggesting a failure to understand its purpose. Likewise, the ambiguity regarding the interpretations of the requisite skills of problem solving, analysis and critical analysis among academics and students suggests considerable scope for misinterpretation, which a dialogic approach may help to alleviate through further discussion.

\section{Application of critical skills}

The level 4 Quality Assurance Agency (QAA) Framework for Higher Education (FHEQ) descriptor stipulates "an ability to evaluate and interpret qualitative and quantitative data, in order to develop lines of argument and make sound judgements in accordance with basic theories and concepts of their subject(s) of study" (QAA, 2014, p. 21). It was suggested that this could be interpreted as expressing criticality through an authorial voice rather than simply synthesising sources. However, this did not appear to be an area which can be addressed in the feedback provided on the assessments examined.

An accommodationist approach to the construction of written texts appeared to be assumed within the Business School. There was an acknowledgement that writing skills should reflect practices within the workplace and that it was necessary that students should learn to conform to the values and culture of corporate institutions and were hence required to "think in a particular way." The vocational nature of many of the modules was also emphasised and there was recognition among participating academics that this resulted in training rather than education and that this might appear to be incongruous with the institutional norms of higher education. The participating academics seems to regard their students as having limited critical thinking skills ("it is unwise to have unrealistic expectations") and "struggled" to construct arguments. However, facilitating the development of critical skills within core modules, through an exploration of disciplinary discourse, was considered impractical due to time constraints and the need to prioritise the transmission of content. The acquisition of such skills seemed to be perceived as external to the discipline and viewed as a deficit arising from the students' previous educational experience.

\section{Conclusion}

The facilitation of the acquisition of critical writing practices is likely to be furthered through an exploration of disciplinary discourse, arising from the interrelationship between participants, practices and modes of communication. An exploration of disciplinary discourse is therefore likely to have an impact on the construction of what is considered to be a "good" academic text and understanding of how critical skills can be applied within the disciplinary context. However, barriers to the successful acquisition of critical thinking skills exist due to the perception that students need to acquire normative behavioural patterns in order to conform to the corporate culture in which they will subsequently need to acculturate into in order to participate within professional spheres. Such an approach is likely to mitigate against an examination of ideological dimensions, a consideration of the ethical or social context or how values, theories and assumptions influence the construction of texts. It is also likely to 
limit discussion of disciplinary complexities and ambiguities. Furthermore, assumptions by both students and academics regarding the unidirectionality of student-teacher relationships may well have mitigated against a truly dialogic approach to facilitate self-directed learning processes, which would be likely to enable learners to successfully engage in the construction of critical written texts. This would appear to negate the constructivist assumption that although skills may be transmitted by means of instruction, the acquisition of abilities is facilitated by creative interaction, thus blurring the distinction between education and training.

\section{References}

Atkinson, D. (1997). A critical approach to critical thinking in TESOL. TESOL Quarterly, 3(1), 71-94.

Bangeni, B., \& Kapp R. (2006). 'I want to write about the Dalai Lama without being penalized?': Literacies in transition. In L Thesen \& E. Van Pletzen (Eds.), Academic literacy and languages of change. (pp. 67-83). London: Continuum Press.

Bakhtin, M. M. (1981). The dialogic imagination: Four essays by MM Bakhtin. Austin: University of Texas Press.

Clark, R., \& Ivanic, R. (1997). The politics of writing. London: Routledge.

Dearing, R. (1997). Higher education in the learning society. The National Committee of Inquiry into Higher Education. London: Her Majesties Stationary Office.

Gee, J. P. (2008). Social linguistics and literacies: Ideology in discourses. (3rd ed.). Oxford: Routledge.

Halliday, M. A. K., \& Webster, J. J. (2000). Continuum companion to systemic functional linguistics. London: Continuum International Publishing Group.

Hamberley-Fletcher, L., \& Hanley, C. (2016). The use of critical thinking in higher education in relation to the international student: Shifting policy and practice. British Educational Research Journal, 42(6), 978-972. http://doi.org/10.1002/berj.3246

Ivanic, R. (1998). Writing and identity: The discoursal construction of identity in academic writing. Amsterdam: John Benjamins.

Jacobs, C. (2005). On being an insider on the outside: New spaces for integrating academic literacies. Teaching in Higher Education, 10(4), 475-487. https://doi.org/10.1080/13562510500239091

Jones, S. (2009). Redisciplining generic attributes: The disciplinary context in focus. Studies in Higher Education, 34(1), 85-100. https: //doi.org /10.1080/ 0307507080260201

Kress, G. (2007). Thinking about meaning and learning in a world of instability and multiplicity. Pedagogies. An International Journal, 2(1), 19-34. https://doi.org/10.1080/15544800701343604

Lea, M. R., \& Street, B. V. (1998). Student writing in higher education: An academic literacies approach. Studies in Higher Education, 23(2), 157-172. https://doi.org/10.1080/03075079812331380364

Lea, M. R. (2004). Academic literacies: A pedagogy for course design. Studies in Higher Education, 29(6), 739-756. https://doi.org/10.1080/0307507042000287230

Lillis, T., \& Scott, M. (2007). Defining academic literacies research: Issues of epistemology, ideology and strategy. Journal of Applied Linguistics, 4(1), 5-32. http://dx.doi.org/doi:10.1558/japl.v4i1.5

McGinley, W. (1992). The role of reading and writing while composing from sources. Reading Research Quarterly, 27(3), 227-343.

Journal of Contemporary Issues in Education, 2020, 15(2), pp. 104-119.

(c) Author(s), Creative Commons Attribution 4.0 (CC BY 4.0) licence

http://ejournals.library.ualberta.ca/index.php/JCIE

doi 10.20355/jcie29417 
Merry, S., Price, M., Carless, D., \& Taras, M. (2013). Reconceptualising feedback in higher education: Developing dialogue with students. London, Routledge.

Moreau, M., \& Leathwood C. (2006). Graduates' employment and the discourse of employability: A critical analysis. Journal of Education and Work, 19, 305-324. https://doi.org/10.1080/13639080600867083

Quality Assurance Agency (2014). The UK quality code for higher education. Gloucester: QAA.

SEEC (2016). Credit level descriptors for higher education. The University of Bedfordshire, Luton: SEEC. https://www.seec.org.uk/wp-content/uploads/2016/07/SEECdescriptors-2016.pdf

Swales, J. (1990). Genre analysis: English in research and academic settings. Cambridge, CUP.

Vygotsky, L. S. (1962). Thought and language. Cambridge: MIT Press.

Wallace, M., \& Wray, A. (2011). Critical reading and writing for postgraduates. London: Sage Publications.

Willingham, D. T. (2007). Critical thinking: Why is it so hard to teach? American Educator, 31, 8-19. https://doi.org/10.3200/AEPR.109.4.21-32

Widdowson, H.G. (1983). Learning purpose and language use. Oxford: Oxford University Press.

Wingate, U., \& Tribble, C. (2012). The best of both worlds? Towards an English for academic purposes/Academic literacies writing pedagogy. Studies in Higher Education, 37 (4), 481-495. https://doi.org/10.1080/03075079.2010.525630

Wingate, U. (2015). Academic literacy and student diversity: The case for inclusive practice. Multilingual Matters.

Wittgenstein, L. (1953). Philosophical investigations. Oxford: Blackwell. 